\title{
Erratum: Dynamic light scattering in network-forming sodium ultraphosphate liquids near the glass transition [Phys. Rev. B 80, 064201 (2009)]
}

R. Fabian, Jr. and D. L. Sidebottom

(Q) (Received 29 July 2019; published 13 August 2019)

DOI: 10.1103/PhysRevB.100.089903

At the time of publication, we were unaware of earlier work by Nemilov [1,2] whose early suggestion that fragility might be correlated with average bond connectivity is relevant to the topic of our paper.

[1] S. V. Nemilov, in Viscosity and Structure of Glass, edited by E. A. Porai-Koshitz, The Structure of Glass, Proceedings of the Fourth All-Union Conference on the Glassy State Vol. 6 (Consultants Bureau, New York, 1966), Pt. 1, p. 58.

[2] S. V. Nemilov, Review: Structural aspect of possible interrelation between fragility (length) of glass forming melts and Poisson's ratio of glasses, J. Non-Cryst. Solids 353, 4613 (2007). 